\title{
Editorial to Theme Issue on Cell Based Therapeutics
}

\author{
Karin H. Hoogendoorn ' (D) Christopher A. Bravery ${ }^{2}$
}

Received: 14 January 2019 / Accepted: 14 January 2019 / Published online: 23 January 2019

(C) Springer Science+Business Media, LLC, part of Springer Nature 2019

The clinical success of transplantation has naturally led to approaches to improve and expand therapeutic options through expansion and other manipulations of cells and tissues, including genetic modification. For health authorities this raises the question of safety and therefore whether such products need to be regulated as medicinal products to safeguard public health.

In the EU, medicines are defined as having an immunologic, metabolic or pharmacologic mechanism of action that corrects or modifies a physiological process. This definition would include transplantation if these were not excluded from the scope of the directive $(1,2)$. Prior to 2009, national health authorities across the EU had a disparate interpretation of how manipulated cell products should be regulated and this uncertainty hindered commercial development. Since 2009, however, such products are required to seek market authorisation from the European Medicines Agency (EMA), and to acknowledge their novelty a new Committee for Advanced Therapies (CAT) was formed to have oversight of these products (called Advanced Therapy Medicinal Products (ATMPs)). The first living cell product to be approved by the EMA was ChondroCelect, a suspension of chondrocytes isolated and expanded from a biopsy of the patient's cartilage. Since then a further 10 living cell based medicinal products have been approved, 4 of these being genetically modified ex vivo by transduction with viral vectors.

In the USA, the Food and Drug Association's (FDA) Center for Biologics Evaluation (CBER) has the regulatory oversight of these innovative medicinal products. Like in Europe, these products can be commercially used only after

Karin $\mathrm{H}$. Hoogendoorn

K.H.Hoogendoorn@lumc.nl

Leids Universitair Medisch Centrum, Leiden, Netherlands

2 Consulting On Advanced Biologicals (CAB) Ltd, London, UK safety and efficacy have been proven through an extensive clinical trial programme. To date, 6 living cell based medicinal products have been approved by the FDA, 2 of these being genetically modified.

There are many reasons why currently only a few products are on the market and many products are still in pre-clinical and early clinical development phases. This theme issue covers pre-clinical, clinical, and pharmaceutical aspects of cell based medicinal products and highlights the challenges for a successful development programme.

Currently one of the most exiting categories of living cell products are those made from the patient's T cells, genetically modified to express a chimeric antigen receptor (CAR-T) to B cell lymphomas. Salmikangas et al. discuss product- and patientrelated variables that may pose challenges for the developers of CAR-T products from scientific and regulatory perspectives (3).

CAR-T cells are just one type of living cell products in a category called "immunotherapies", products that aim to harness the patient's own immune system to overcome cancers. Karlsson-Parra et al. present pre-clinical mode of action data, quality (chemical, manufacturing and control (CMC)) data, and initial clinical data on ilixadencel, a dendritic cell based immunotherapy for the treatment of various solid tumours (4).

Developing living cell products is not without its own unique issues, one being how to generate pre-clinical evidence to support the first-in-human trial. McBlane et al. discuss these problems with a primary focus on the European regulatory framework (5).

On the theme of technical difficulties to develop a good quality product (i.e., consistently manufactured, tested, and stable) even apparently simple measurements such as cell counting and viability determination can pose surprising difficulties. Jiskoot et al. investigate the potential of two flow imaging microscopy (FIM) techniques (Micro-Flow Imaging (MFI) and FlowCAM) to determine total cell concentration and cell viability in cell based products (Sediq et al 2018).

C.A. Bravery and K.H. Hoogendoorn, theme editors. 
Publisher's note Springer Nature remains neutral with regard to jurisdictional claims in published maps and institutional affiliations.

\section{REFERENCES}

1. Bravery CA. Regulating interface science healthcare products: myths and uncertainties. J R Soc Interface. 2010;7(Suppl. 6):S789-95.

2. Bravery CA. A CATalyst for change: regulating regenerative medicines in Europe. In: Prescott CD, Polak JM, editors. The delivery of regenerative medicines and their impact on healthcare. Boca Raton: CRC; 2011.

3. Salmikangas P, Kinsella N, Chamberlain P. Chimeric antigen receptor T-cells (CAR T-cells) for Cancer immunotherapy - moving target for industry? PharmRes. 2018;35:152.
4. Karlsson-Parra A, Kovacka J, Heimann E, Jorvid M, Zeilemaker S, Longhurst $\mathrm{S}$, et al. Ilixadencel - an allogeneic cell-based anticancer immune primer for intratumoral administration. PharmRes. 2018;35:156.

5. McBlane JW, Phul P, Sharpe M. Preclinical development of cellbased products: a European regulatory science perspective. PharmRes. 2018;35:165.

6. Sediq A.D., , Klem R., Nejadnik M.R., Meij P., Jiskoot W. Labelfree, flow-imaging methods for determination of cell concentration and viability. PharmRes (2018) 35: 150. 